\title{
CD43 cross-linking increases the Fas-induced apoptosis through induction of Fas aggregation in Jurkat T-cells
}

\author{
Hae Jung Kim, Hyo Jin Park², \\ Weon Seo Park ${ }^{1}$ and Youngmee $\mathrm{Bae}^{3,4}$ \\ ${ }^{1}$ Division of Specific Organ Cancer, \\ Research Institute National Cancer Center \\ Goyang 411-769, Korea \\ 2Department of Pathology \\ ${ }^{3}$ Department of Parasitology \\ Seoul National University College of Medicine \\ Seoul 110-799, Korea \\ ${ }^{4}$ Corresponding author: Tel, 82-2-740-8345; \\ Fax, 82-2-765-6142; E-mail, ymbae@snu.ac.kr
}

Accepted 30 May 2006

Abbreviation: TcR, T-cell receptor

\begin{abstract}
CD43 (sialophorin, leukosialin) is a heavily sialylated surface protein expressed on most leukocytes and platelets including T cells. Although CD43 antigen is known to have multiple and complex structure, exact function of CD43 in each cell type is not completely understood. Here we evaluated the role of CD43 in Fas (CD95)-induced cell death in human T lymphoblastoid cell line, Jurkat. Crosslinking CD43 antigen by $\mathrm{K} 06 \mathrm{mAb}$ increased the Fas-mediated Jurkat cell apoptosis and the augmentation was inhibited by treatment with caspase inhibitors. Further, CD43 signaling of Jurkat cells induced Fas oligomerization on the cell surfaces implying that CD43 ligation have effects on early stage of Fas-induced T cell death. These also suggest that CD43 might play an important role in contraction of the immune response by promotion of Fas-induced apoptosis in human T cells.
\end{abstract}

Keywords: apoptosis; antigens, CD43; antigens, CD95; caspase; Jurkat cells; T-lymphocytes

\section{Introduction}

Lymphocyte homeostasis is a balance between lymphocyte proliferation and death. Tight control of apoptosis is essential for immune functions, because its altered regulation can result in cancers and autoimmunity. There is an active process leading to death caused by the stimulation of death-inducing molecules including Fas and TNF-receptor (TNFR)1, members of the expanding TNFR superfamily (Lenardo et al. 1999). Cross-linking of surface Fas molecules (CD95, Apo-1) by the Fas ligand (FasL) or agonistic anti-Fas Abs activates apoptotic death programs (Nagata and Goldstein, 1995; Wallach et al., 1999; Kim et al., 2000) via homo-oligomerization of these death receptors and results in the cleavage of several intracellular substrates (Medema et al., 1997; Thornberry and Lazebnik, 1998; Muzio et al., 1998).

There are several cell surface antigens and factors that might regulate the sensitivity of $T$ cells to FasL and TNF. One of the most immunologically important means of facilitating $T$ cell death by FasL or TNF is through TCR occupancy (Wong et al., 1997). In addition, interleukin (IL)-2 also enhances Fas-mediated apoptosis in human T cells (Fournel et al., 1996) and other antigens including CD45 and CD99 have been implicated in augmentation of Fasmediated cell death (Klaus et al., 1996; Jung et al., 2003).

CD43 (sialophorin, leukosialin, or gp115) is a large sialoglycoprotein that is abundantly expressed by cells of hematopoietic origin, including both CD4+ and CD8+ T cells (Axelsson et al., 1985; Borche et al., 1987; Remold-O'Donnell et al., 1987). This abundant surface protein CD43 is a transmembrane protein consisting of a highly O-glycosylated extracellular domain of 235 amino acids, a transmembrane domain of 23 amino acids, and an intracytoplasmic domain of 123 amino acids (Pedraza-Alva et al., 1998). Posttranslational modifications result in two glycoforms of CD43. Resting $T$ lymphocytes express a CD43 isoform of 113-122 kDa that contains O-linked tetrasaccharides attached to serine and threonine residues. Upon activation, T lymphocytes express a 125-135kDa form of CD43 carrying mainly O-linked hexasaccharides (Piller et al., 1988; Piller et al., 1991).

Previous studies suggest that CD43 may regulate multiple cellular functions, such as cell adhesion, activation, and proliferation as well as cell survival and apoptosis. However, the precise function of CD43 in each cell type remains unclear due to conflicting results. Cross-linking of CD43 may enhance T cell proliferation (Park et al., 1991), or can act as a costimulatory molecule independent of 
CD28 (Sperling et al., 1995). On the contrary, T cells from CD43-deficient mice are hyper-responsive following both in vivo and in vitro activation, indicating a negative regulatory role of CD43 in down modulation of effector $\mathrm{T}$ cell response (Manjunath et al., 1995; Thurman et al., 1998). In addition, antiapoptotic and proapoptotic functions of CD43 have been reported. Certain studies have shown that engagement of CD43 induces apoptosis of T cells and hematopoietic progenitor cells (Bazil et al., 1995; Brown et al. 1996; Cermak et al., 2002; Park et al., 2004). However, He and Bevan have reported that high level expression of CD43 inhibits $\mathrm{T}$ cell receptor (TCR)/CD3 mediated apoptosis (1999).

Here, we propose another proapoptotic function of CD43 through the mechanism that modulates Fas induced cell death in human $\mathrm{T}$ lymphoblastoid cell line. CD43 cross-linking increases the Fas-induced apoptosis through the induction of Fas aggregation in Jurkat cells. Therefore, we come to a conclusion that CD43 is related with the Fas-induced apoptosis in Jurkat cell, and this might have some implications in activation induced cell death (AICD) of human $T$ cells.

\section{Materials and Methods}

\section{Cells and reagents}

Jurkat cells were maintained in RPMI-1640 containing $10 \%$ fetal calf serum (FCS, Hyclone, Logan, UT), $2 \mathrm{mM}$ L-glutamine, $50 \mu \mathrm{M} \beta$-mercaptoethanol (ME), $10 \mathrm{mM} \mathrm{HEPES}$ and $100 \mathrm{U} / \mathrm{ml}$ each of penicillin and streptomycin. Antibodies against Fas protein were purchased from Medical \& Biological Laboratory (clone $\mathrm{CH} 11$; Nagoya, Japan) and Santa Cruz Biotechnology (clone C-20; Santa Cruz, CA). Antimouse Ig antisera coupled to horseradish peroxidase (HRP) were also from Santa Cruz Biotechnology. The caspase inhibitors, z-VAD-fmk, z-DEVD$\mathrm{CHO}$, and z-IETD-fmk were from Calbiochem (La Jolla, CA). Anti-human CD43 mAb, K06, was produced and purified as previously described (Park et al., 2004).

\section{Flow cytometric analysis}

Jurkat cells were plated in 24-well plate (Falcon, Becton-Dickinson, Franklin Lakes, NJ) at $2 \times 10^{5}$ cells/well in a final volume of $1 \mathrm{ml}$ of RPMI medium. These cells were treated by anti-Fas mAb, CH11, with or without anti-CD43 mAb, K06. At various time points, cells were harvested and used for apoptosis or western blot analyses. To evaluate the rate of apoptosis, cells were incubated with FITC-conjugated Annexin V. For the detection of early and late apoptosis by flow cytometry, double staining of Anneixn $V$ and the vital dye 7-AAD was performed. The cells were washed three times with Annexin V-binding buffer (0.1 M HEPES/NaOH [pH7.4], 1.4 M $\mathrm{NaCl}, 25 \mathrm{mM} \mathrm{CaCl}_{2}$ ) and were incubated for $30 \mathrm{~min}$ at room temperature in the dark in Annexin V-binding buffer containing FITC-conjugated annexin $V$ and 20 $\mu \mathrm{g} / \mathrm{ml}$ 7-AAD. This double-staining shows both early (Annexin $\mathrm{V}^{+} / 7-\mathrm{AAD}^{-}$) and late apoptotic cells (Annexin $\mathrm{V}^{+} / 7-A A D^{+}$). Stained cells were analyzed using a FACScalibur (Becton-Dickinson, Mountain View, CA) and data were analyzed using Cellquest software.

\section{Treatment of caspase inhibitors}

Jurkat cells were treated with caspase inhibitors, 20 $\mu \mathrm{M}$ caspase inhibitor I (z-VAD-fmk), $20 \mu \mathrm{M}$ caspase3 inhibitor (z-DEVD-CHO), or $50 \mu \mathrm{M}$ caspasse-8 inhibitor (z-ITED-fmk), for $2 \mathrm{~h}$ prior to the addition of $\mathrm{CH} 11$ and/or K06 mAbs. After $5 \mathrm{~h}$ incubation, cells were harvested and analyzed to evaluate the effect of caspase inhibitors on Jurkat cell death.

\section{Detection of Fas aggregation}

Analysis of SDS-stable Fas microaggregates was performed as described previously (Algeciras-Schimnich et al., 2002). In brief, $3 \times 10^{6}$ cells were stimulated with $5 \mu \mathrm{g} / \mathrm{ml} \mathrm{K06}$ for $2 \mathrm{~h}$ at $37^{\circ} \mathrm{C}$ and the cells were washed with PBS and lysed in lysis buffer (50 mM HEPES [pH7.4], $150 \mathrm{mM} \mathrm{NaCl}, 10 \mathrm{mM} \mathrm{NaF}$, $10 \mathrm{mM}$ iodoacetamine, $200 \mu \mathrm{M} \mathrm{Na} \mathrm{VO}_{4}, 1 \% \mathrm{NP}-40$ ). Cell extracts were separated by SDS-PAGE, transferred electrophoretically onto Immobilon $P$ (Millipore, Billerica, MA) and probed with C-20 Ab against Fas. The specific bands were visualized using $E C L$ system (Amersham Pharmacia Biotech, Buckinghamshire, England).

\section{Confocal analysis}

Jurkat cells were pretreated with $\mathrm{K} 06 \mathrm{mAb}$ and rabbit anti-mouse polyclonal antibody, and then adhered to the poly-L-lysine coated slide. As a negative control, isotype matched irrelevant mAb was treated. The cells were fixed with paraformaldehyde and were incubated with biotinylated anti-Fas mAb (Pharmingen, Becton-Dickinson) and streptavidin-alexa (Molecular Probes, OR). The stained preperations were analyzed on a confocal microscope (Radiance 2000, Bio-Rad Laboratories, Hercules, CA). 


\section{Results}

\section{Engagement of anti-CD43 mAb enhances Fas- mediated cell death in Jurkat cells}

In order to evaluate the role of CD43 in Fasmediated apoptosis of $T$ cells, Jurkat cells were treated with anti-CD43 mAb, K06, along with an agonistic anti-Fas $\mathrm{mAb}, \mathrm{CH} 11$, and phosphatidylserine exposure was analyzed by Annexin- $V$ staining (Figure 1). When the cells were treated with K06 mAb alone, apoptosis of Jurkat cells was not

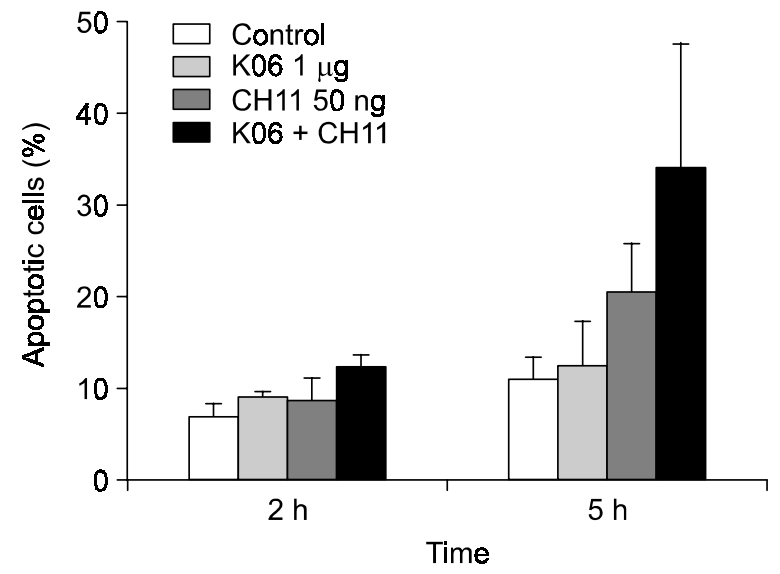

Figure 1. Augmentation of Fas-mediated apoptosis in Jurkat cells by anti-CD43 mAb, K06. Jurkat cells were incubated with $1 \mu \mathrm{g} / \mathrm{ml} \mathrm{K06} \mathrm{in}$ the presence, or absence of $50 \mathrm{ng} / \mathrm{ml}$ anti-Fas $\mathrm{mAb}$ (CH11). At the time point indicated, cells were harvested and analyzed apoptosis using Annexin-V staining and flow cytometry. When the cells were treated with $\mathrm{KO} 6$ and $\mathrm{CH} 11$, the degree of apoptotic cells was higher than $\mathrm{CH} 11$ alone. The values were average and standard deviation of five independent experiments. observed as previously reported (Park et al., 2004). In the cells treated with anti-Fas mAb $\mathrm{CH} 11$, Fas-induced cell death was observed in about $20 \%$ of the cells as previously described (Wallach et al., 1999). When the cells were co-ligated with $\mathrm{CH} 11$ and $\mathrm{K} 06$, the percentage of apoptotic cells was higher than that of the cells treated with $\mathrm{CH} 11$ alone (Figure 1). These data showed that signal through CD43 alone did not induce the cell death in Jurkat cells, but engagement of CD43 antigen increased the Fas-mediated apoptosis of Jurkat cells.

To evaluate whether the augmentation of Fasmediated cell death by the CD43 ligation is dependent on the amounts of $\mathrm{CH} 11 \mathrm{mAb}$, we added various concentrations of $\mathrm{CH} 11 \mathrm{mAb}$ to the Jurkat cells. When the cells were treated with $50 \mathrm{ng} / \mathrm{ml}$ anti-Fas $\mathrm{mAb} \mathrm{CH} 11$ alone, $16 \%$ of cells appeared to be in early apoptosis (Annexin $\mathrm{V}^{+} / 7-\mathrm{AAD}^{-}$, Figure 2 ). The percentage of early apoptotic cells was increased to $38 \%$ when the cells were co-ligated with $\mathrm{CH} 11$ and K06 mAbs (Figure 2). However, the percentage of late apoptosis (Annexin $\mathrm{V}^{+} / 7 \mathrm{AAD}^{+}$) was not significantly changed upon $\mathrm{K} 06$ engagement $(1.7 \%$ vs. $3.4 \%)$. This implies that K06 ligation signals the initial step of apoptosis in Fas mediated $T$ cell death. Maximum effect of CD43 mediated augmentation of Fas induced cell death was observed when $50 \mathrm{ng} / \mathrm{ml}$ of $\mathrm{CH} 11 \mathrm{mAb}$ was added to the Jurkat cells. In addition, enhanced cell death was not proportional to the $\mathrm{CH} 11 \mathrm{mAb}$ added (Figure 2).

The augmentation of Fas-mediated apoptosis via anti-CD43 mAb (K06) is related to early events of caspase activation

It is well known that caspases play a pivotal role in
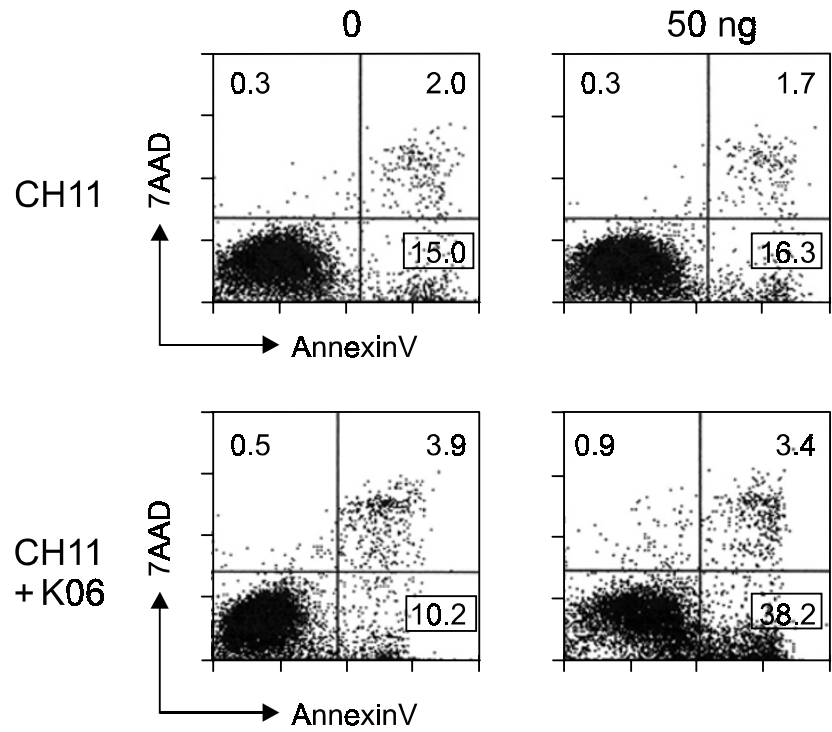
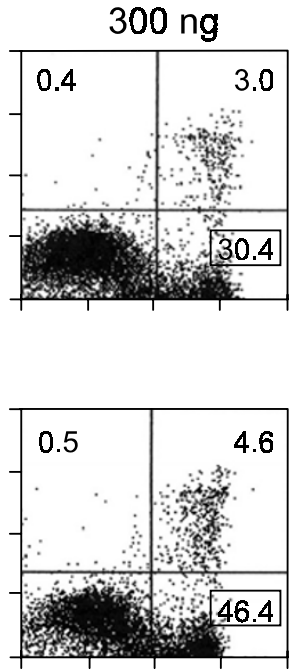

Figure 2. The effect of $\mathrm{CH} 11$ concentration on the K06-amplified Fas-induced apoptosis. K06-amplified Fasinduced apoptosis was not increased by the increment of $\mathrm{CH} 11$ concentration (50 or $300 \mathrm{ng} / \mathrm{ml}$ ). Jurkat cells $\left(2 \times 10^{5} / \mathrm{ml}\right)$ were incubated with indicated amounts of $\mathrm{CH} 11$ with or without anti-CD43 mAb (K06). The K06 $\mathrm{mAb}$ was used as $5 \mu \mathrm{g} / \mathrm{ml}$. After $5 \mathrm{~h}$ incubation, cell death was assayed by Annexin- $V$ and $7 A A D$ staining. This result was representative of five independent experiments. 


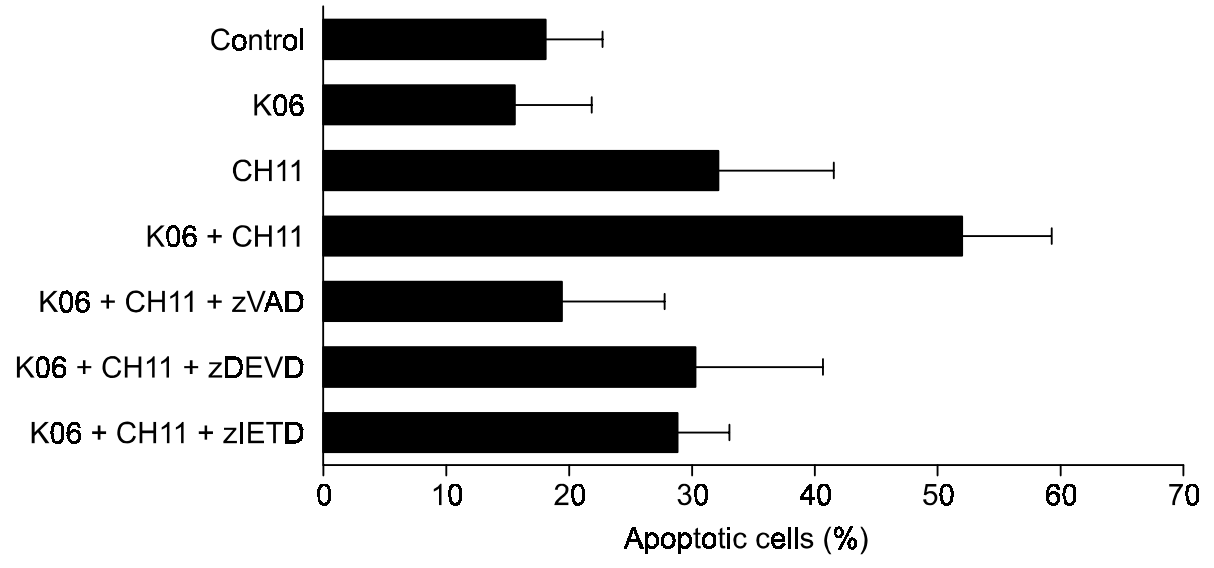

Figure 3. Effects of caspase inhibitors on the K06-amplified apoptosis. Cells $\left(2 \times 10^{5} / \mathrm{ml}\right)$ were incubated with $\mathrm{K} 06(5 \mu \mathrm{g} / \mathrm{ml})$ and CH11 (100 ng/ml) for 5 h. $20 \mu \mathrm{M}$ of zVAD-fmk, $20 \mu \mathrm{M}$ of zDEVDfmk, or $50 \mu \mathrm{M}$ of zIETD-fmk was added to block the caspase activation. After $5 \mathrm{~h}$ incubation, the degree of apoptosis was determined by using Annexin-V staining and analyzed by flow cytometry. The values in this figure were average and standard deviation of three independent experiments.
Fas-mediated apoptosis. On binding to cognate ligands or agonistic antibodies, Fas aggregates initiate the activation of caspase-8, which is followed by a cascade of caspase activation. To clarify which step in pathway of Fas-mediated apoptosis is involved in the CD43-amplified Fas-induced cell death, we added the caspase inhibitors, z-VAD, z-DEVD and z-IETD. Treatment with pan caspase inhibitor, z-VAD-fmk, blocked completely the K06mediated augmentation of Fas-mediated cell death (Figure 3). Next, a caspase-8 inhibitor, z-IETD-fmk, and a caspase- 3 inhibitor, z-DEVD-fmk, were used to block specific events in the Fas pathway. As shown in Figure 3, both caspase-3 and caspase-8 inhibitors also diminished the K06-mediated augmentation of Fas-induced apoptosis. These findings imply that K06-mediated apoptosis of Jurkat cells is dependent on Fas signal and the K06 signal affects early events of Fas-mediated apoptosis.

\section{Ligation of anti-CD43 mAb (K06) induces aggregation of Fas molecules on the cell surface}

When Fas interacts with FasL or agonistic anti-Fas Abs, Fas molecules are trimerized and caspase- 8 is subsequently activated (Chinnaiyan et al., 1995). When Jurkat cells were treated with K06 mAb, no increment of Fas expression on the cell surface was observed by flow cytometric analysis (data not shown). Furthermore, as shown in Figure 3, CD43 ligation seemed to have an effect on the early stage of Fas-induced apoptosis pathway, possibly upstream of caspase 8 activation.

As a consequence, we next assessed whether the aggregation of Fas molecules on the cell surface could be induced by $\mathrm{K} 06 \mathrm{mAb}$ treatments. Jurkat cells were treated with 2 or $10 \mu \mathrm{g}$ of $\mathrm{K} 06 \mathrm{mAb}$ for 30 min or $2 \mathrm{~h}$, and western blot analysis was performed to visualize Fas-aggregates. As shown in Figure 4A, formation of SDS- and 2-ME-stable, high $M_{\mathrm{r}}$ aggre-
A

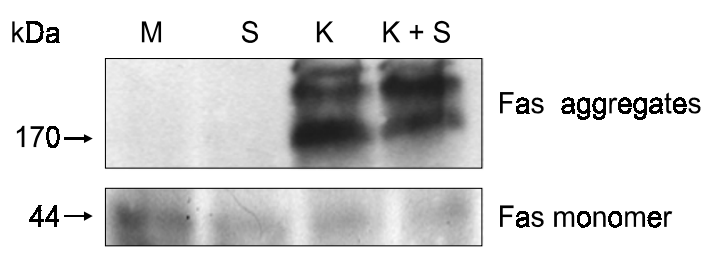

B

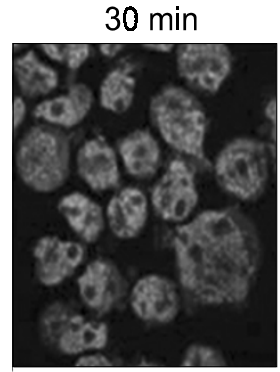

$2 \mathrm{~h}$
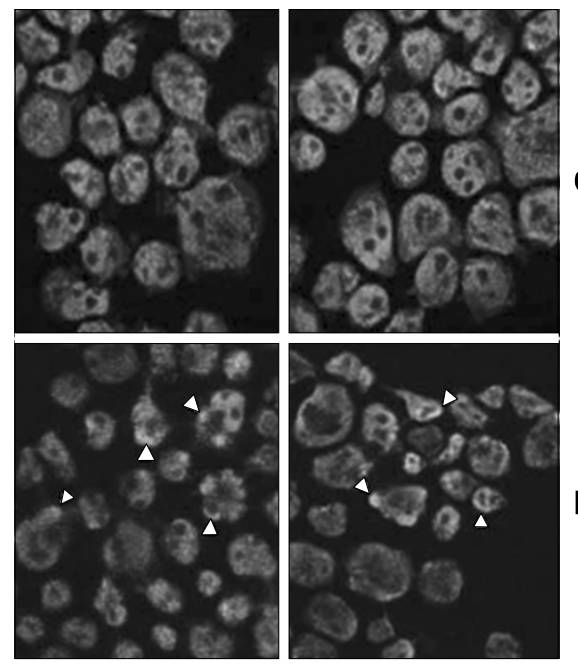

Control

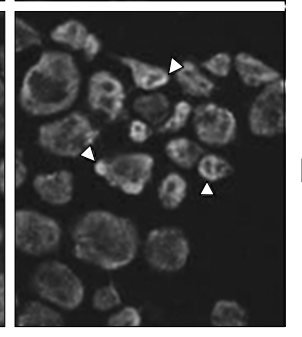

K06 ligation

Figure 4. K06 induced aggregation of Fas molecules. (A) Jurkat cells $\left(5 \times 10^{6} / \mathrm{ml}\right)$ were treated as indicated condition for $5 \mathrm{~h}$ (M: media only, S: secondary Ab only (anti-mouse lg $20 \mu \mathrm{g} / \mathrm{ml}), \mathrm{K}$ : K06 $(10 \mu \mathrm{g} / \mathrm{ml})$, $\mathrm{K}+\mathrm{S}$ : (K06 and secondary $\mathrm{Ab})$ ). Total cell lysates were prepared and western blot analysis was performed. (B) Confocal analysis of immunostained Jurkat cells using biotinylated-mAb against Fas. The cells were pretreated with $\mathrm{K} 0610 \mu \mathrm{g} / \mathrm{ml}$ and secondary antibody (K06 ligation) or the secondary Ab (anti-mouse lg) $20 \mu \mathrm{g} / \mathrm{ml}$ only (control) for indicated time. At each time point, cells were harvested and staining was applied using anti-Fas Ab. Arrow heads indicate patch-shaped aggregation of the Fas molecules on the cell surface. 
gates ( $>200 \mathrm{kDa}$ ) of Fas antigens were detected in lysates of K06 only or K06 and the secondary Ab treated cells. The formation of the high $M_{\mathrm{r}}$ aggregates increased with time and the amount of mAb added (data not shown), while aggregation of Fas was not observed in the control cells treated with irrelevant $\mathrm{mAb}$. These results indicate that CD43 ligation via the K06 epitope induced Fas aggregation in the absence of Fas-engagement. Confocal analysis also revealed the Fas aggregation induced by K06 mAb treatment. After Jurkat cells were treated with anti-CD43 mAb, K06, for indicated time points, Fas molecules were visualized and analyzed by confocal microscopy. The aggregated Fas molecules were located on the cell membrane as patch-shape as compared with those in the negative control (Figure 4B). Therefore, the CD43 signal via the K06 $\mathrm{mAb}$ induced aggregation of Fas molecules in Jurkat $\mathrm{T}$ cells without FasL or agonistic anti-Fas mAb treatment.

\section{Discussion}

Receptor mediated apoptotic signaling in hematopoietic cells is carried out primarily by the death receptors of the tumor necrosis factor family. However, the cross-linking of other cell surface receptors such as major histocompatibility complex class I, CD45, CD47, and CD99 could also induce apoptosis (Klaus et al., 1996; Skov et al., 1997; Pettersen et al., 1999; Pettersen et al., 2001). It has been controversial whether ligation of CD43 with $\mathrm{mAb}$ induces apoptosis of hematopoietic cells, especially in T cells (Bazil et al., 1995; Brown et al., 1996; He and Bevan, 1999; Cermak et al., 2002). Treatment of Jurkat cells with anti-CD43 mAb, J393, alone killed $25-50 \%$ of the cell population, while concomitant engagement of the CD3-TcR complex significantly potentiated this effect and a blocking antibody to CD95/Fas receptor could not prevent J393/CD43-induced apoptosis (Brown et al., 1996). Moreover, ligation with anti-CD43 mAb induced tyrosine phosphorylation and inhibited the DNA binding activities of the transcription factors, such as AP-1 and NF-kB (Brown et al., 1996; Cermak et al., 2002). However, opposite results have been reported that high level expression of CD43 inhibits T cell receptor (TCR)/CD3 mediated apoptosis (He and Bevan, 1999).

In this study, we evaluated the functional role of CD43 in T cell death using anti-CD43 mAb, K06, we produced (Park et al., 2004) and found another mechanism for CD43 to enhance apoptosis in Jurkat cells. Although CD43 ligation through the K06 epitope failed to induce apoptosis in Jurkat cells (Park et al., 2004), K06 signal enhanced Fas-mediated cell death (Figure 1). Apparently, this implies that the cell-specific environment, the nature of the CD43 epitope involved, or cell type-dependent changes in the glycosylation of CD43 could affect the final outcome of CD43-mediated signaling.

Next, we dissected the mechanisms of enhancement of Fas-mediated apoptosis by K06 signal in Jurkat cells. First, we considered the possibility that the expression of Fas molecules on the cell surface is enhanced by the K06 treatment. However, K06 engaged Jurkat cells showed no increment of Fas expression on the cell surface as analyzed by flow cytometric analysis (data not shown). These indicate that increased apoptosis of Jurkat cells by CD43 cross-linking is not resulted from up-regulation of Fas molecules on the cell surfaces.

Fas ligation via the FasL or an agonistic anti-Fas $\mathrm{Ab}$ induces Fas oligomerization, recruits Fas-associated adaptor and effector proteins leading to formation of large Fas surface clusters, and results in caspase activation (Wallach et al., 1999; AlgecirasSchimnich et al., 2002). To understand if the caspases are involved in K06-amplified Fas-induced apoptosis, caspase inhibitors are added prior to the addition of mAbs. Caspase- 8 inhibitor as well as caspase-3 inhibitor was able to inhibit the augmentation of Fas-induced cell death (Figure 3). Therefore, the signaling pathway of K06 induced augmentation in Fas-mediated apoposis might be involved in the initial signaling event, possibly caspase- 8 activation or the earlier events. To confirm whether CD43 signal could induce Fas oligomerization before $\mathrm{CH} 11$ ligation, we performed western blot analysis and confocal microscopic examination. As shown in Figure $4 A$ and $B$, oligomerized Fas molecules were readily observed on cross-linking of anti-CD43 mAb, K06, alone. There have been some conflicts whether Fas aggregation correlates with Fas-mediated apoptosis. However, not only the Fas oligomerization by Fas ligation but preassociated receptor complex of Fas have been revealed necessary for Fas signaling and dominant interference in human disease. In addition, Siegel et al. also demonstrated that Fas complexes from surface-cross linked cells showed only partial recruitment of FADD and no recruitment of caspase-8, with no cleavage of the downstream caspase substrate poly (ADP-ribose) polymerase (2000). This implies that Fas signal through the Fas molecule is requisite to complete apoptosis and therefore pre-associated receptor complex of Fas by CD43 cross-linking itself was not able to induce apoptosis in our system. Further, the formation of Fas aggregates by cross-linking of CD43 might increase the $\mathrm{CH} 11$-mediated apoptosis of Jurkat 
cells without the change of Fas expression level on the cell surface (Figure 4 and data not shown).

In addition, the Fas cell membrane polarization in long term activated $\mathrm{T}$ lymphocytes, through an ezrin-mediated association with the actin cytoskelecton, is a key intracellular mechanism in rendering human $\mathrm{T}$ lymphocytes susceptible to the Fasmediated apoptosis (Parlato et al., 2000). Further, the cytoplasmic tail of CD43 has been shown to interact with members of the ezrin-radixin-moesin (ERM) family of cytoskelectal adaptor molecules (Yonemura et al., 1998). Most recently, it has been shown that CD43 is excluded from the immunological synapse during $T$ cell activation, and this exclusion appears to be mediated by an ezrinradixin-moesin-dependent mechanism(s) (Sperling et al., 1998; Allenspach et al., 2001; Delon et al., 2001). Based on these findings and our present data, we propose an alternate mechanism; CD43 molecule might regulate the activation induced cell death in human $T$ cells through ezrin and Fas molecules. Full T cell activation involves a complete membrane reorganization event. In parallel with the formation of the immunological synapse at the contact sites between the T cell and the APC, a second "anti-synapse" forms at the distal pole in which CD43 anchored with ezrin is located. Another signal through CD43 might promote association of Fas and cytoskeleton molecules, ezrin, and results in aggregation of Fas molecules on the cell surface. These would render activated human $T$ lymphocytes susceptible to Fas-mediated apoptosis and play an important role in maintaining $\mathrm{T}$ cell homeostasis.

\section{Acknowledgement}

This work was supported by (KRF-2001-015-FP0083) from Korean Research Foundation and Korea Science and Engineering Foundation through the RRC (Rheumatism Research Center) at Catholic University (R11-2002-098-06002-0).

\section{References}

Algeciras-Schimnich A, Shen L, Barnhart BC, Murmann AE, Burkhardt JK, Peter ME. Molecular ordering of the initial signaling events of CD95. Mol Cell Biol 2002;22:207-20

Allenspach EJ, Cullinan P, Tong J, Tang Q, Tesciuba AG, Cannon JL, Takahashi SM, Morgan R, Burkhardt JK, Sperling Al. ERM-dependent movement of CD43 defines a novel protein complex distal to the immunological synapse. Immunity 2001;15:739-50

Axelsson B, Hammarstrom S, Finne J, Perlmann P. The large sialoglycoprotein of human lymphocytes. II. Biochemical features. Eur J Immunol 1985;15:427-33

Bazil V, Brandt J, Tsukamoto A, Hoffman R. Apoptosis of human hematopoietic progenitor cells induced by crosslinking of surface CD43, the major sialoglycoprotein of leukocytes. Blood 1995;86:502-11

Borche L, Lozano F, Vilella R, Vives J. CD43 monoclonal antibodies recognize the large sialoglycoprotein of human leukocytes. Eur J Immunol 1987;17:1523-26

Brown TJ, Shuford WW, Wang WC, Nadler SG, Bailey TS, Marquardt H, Mittler RS. Characterization of a CD43/leukosialin-mediated pathway for inducing apoptosis in human T-lymphoblastoid cells. J Biol Chem 1996;271:27686-95

Cermak L, Simova S, Pintzas A, Horejsi V, Andera L. Molecular mechanisms involved in CD43-mediated apoptosis of TF-1 cells. Roles of transcription Daxx expression, and adhesion molecules. J Biol Chem 2002;277:7955-61

Chinnaiyan AM, O'Rourke K, Tewari M, Dixit VM. FADD, a novel death domain-containing protein, interacts with the death domain of Fas and initiates apoptosis. Cell 1995;81: 505-12

Delon J, Kaibuchi K, Germain RN. Exclusion of CD43 from the immunological synapse is mediated by phosphorylationregulated relocation of the cytoskeletal adaptor moesin. Immunity 2001;15:691-701

Fournel S, Genestier L, Robinet E, Flacher M, Revillard JP. Human T cells require IL-2 but not G1/S transition to acquire susceptibility to Fas-mediated apoptosis. J Immunol 1996; 157:4309-15

He YW, Bevan MJ. High level expression of CD43 inhibits T cell receptor/CD3-mediated apoptosis. J Exp Med 1999; 190:1903-8

Jung KC, Kim NH, Park WS, Park SH, Bae Y. The CD99 signal enhances Fas-mediated apoptosis in the human leukemic cell line, Jurkat. FEBS Lett 2003;554:478-84

Kim KM, Lee K, Hong YS, Park HY. Fas-mediated apoptosis and expression of related genes in human malignant hematopoietic cells. Exp Mol Med 2000;32:246-54

Klaus SJ, Sidorenko SP, Clark EA. CD45 ligation induces programmed cell death in T and B lymphocytes. J Immunol 1996;156:2743-53

Lenardo M, Chan KM, Hornung F, McFarland H, Siegel R, Wang J, Zheng L. Mature T lymphocyte apoptosis--immune regulation in a dynamic and unpredictable antigenic environment. Annu Rev Immunol 1999;17:221-53

Medema JP, Scaffidi C, Kischkel FC, Shevchenko A, Mann M, Krammer PH, Peter ME. FLICE is activated by association with the CD95 death-inducing signaling complex (DISC). EMBO J 1997; 16:2794-804

Muzio M, Stockwell BR, Stennicke HR, Salvesen GS, Dixit VM. An induced proximity model for caspase-8 activation. J Biol Chem 1998;273:2926-30

Nagata S, Golstein P. The Fas death factor. Science 1995; 267:1449-56

Park JK, Rosenstein YJ, Remold-O'Donnell E, Bierer BE, Rosen FS, Burakoff SJ. Enhancement of T-cell activation by the CD43 molecule whose expression is defective in Wiskott-Aldrich syndrome. Nature 1991;350:706-9 
Park WS, Chae JS, Jung KC, Choi WJ, Kook MC, Bae Y. Production and the characterization of monoclonal antibody against CD43, K06. Tissue Antigens 2004;63:46-53

Parlato S, Giammarioli AM, Logozzi M, Lozupone F, Matarrese P, Luciani F, Falchi M, Malorni W, Fais S. CD95 (APO-1/Fas) linkage to the actin cytoskeleton through ezrin in human $T$ lymphocytes: a novel regulatory mechanism of the CD95 apoptotic pathway. EMBO J 2000;19:5123-34

Pedraza-Alva G, Merida LB, Burakoff SJ, Rosenstein Y. T cell activation through the CD43 molecule leads to Vav tyrosine phosphorylation and mitogen-activated protein kinase pathway activation. J Biol Chem 1998;273:14218-24

Pettersen RD, Bernard G, Olafsen MK, Pourtein M, Lie SO. CD99 signals caspase-independent T cell death. J Immunol 2001;166:4931-42

Pettersen RD, Hestdal K, Olafsen MK, Lie SO, Lindberg FP. CD47 signals T cell death. J Immunol 1999;162: 7031-40

Piller F, Le Deist F, Weinberg KI, Parkman R, Fukuda M. Altered O-glycan synthesis in lymphocytes from patients with Wiskott-Aldrich syndrome. J Exp Med 1991;173:1501-10

Piller F, Piller V, Fox RI, Fukuda M. Human T-lymphocyte activation is associated with changes in O-glycan biosynthesis. J Biol Chem 1988;263:15146-50

Remold-O'Donnell E, Zimmerman C, Kenney D, Rosen FS. Expression on blood cells of sialophorin, the surface glycoprotein that is defective in Wiskott-Aldrich syndrome. Blood 1987;70:104-9

Siegel RM, Frederiksen JK, Zacharias DA, Chan FK, Johnson M, Lynch D, Tsien RY, Lenardo MJ. Fas preassociation required for apoptosis signaling and dominant inhibition by pathogenic mutations. Science 2000;288:2354-7

Skov S, Klausen P, Claesson MH. Ligation of major histocompatability complex (MHC) class I molecules on human $\mathrm{T}$ cells induces cell death through PI-3 kinase-induced c-Jun $\mathrm{NH} 2$-terminal kinase activity: a novel apoptotic pathway distinct from Fas-induced apoptosis. J Cell Biol 1997;139: 1523-31
Sperling AI, Green JM, Mosley RL, Smith PL, DiPaolo RJ, Klein JR, Bluestone JA, Thompson CB. CD43 is a murine T cell costimulatory receptor that functions independently of CD28. J Exp Med 1995;182:139-46

Sperling AI, Sedy JR, Manjunath N, Kupfer A, Ardman B, Burkhardt JK. TCR signaling induces selective exclusion of CD43 from the T cell-antigen-presenting cell contact site. J Immunol 1998;161:6459-62

Takahashi T, Tanaka M, Brannan Cl, Jenkins NA, Copeland NG, Suda T, Nagata S. Generalized lymphoproliferative disease in mice, caused by a point mutation in the Fas ligand. Cell 1994;76:969-76

Thornberry NA, Lazebnik Y. Caspases: enemies within. Science 1998;281:1312-6

Thurman EC, Walker J, Jayaraman S, Manjunath N, Ardman $\mathrm{B}$, Green JM. Regulation of in vitro and in vivo T cell activation by CD43. Int Immunol 1998;10:691-701

Wallach D, Varfolomeev EE, Malinin NL, Goltsev YV, Kovalenko AV, Boldin MP. Tumor necrosis factor receptor and Fas signaling mechanisms. Annu Rev Immunol 1999;17:331-67

Watanabe-Fukunaga R, Brannan Cl, Copeland NG, Jenkins NA, Nagata S. Lymphoproliferation disorder in mice explained by defects in Fas antigen that mediates apoptosis. Nature 1993;356:314-7

Wong B, Arron J, Choi Y. T cell receptor signals enhance susceptibility to Fas-mediated apoptosis. J Exp Med 1997; 186:1939-44

Wu J, Zhou T, Zhang J, He J, Gause WC, Mountz JD. Correction of accelerated autoimmune disease by early replacement of the mutated Ipr gene with the normal Fas apoptosis gene in the T cells of transgenic MRL-Ipr/lpr mice. Proc Natl Acad Sci USA 1994;91:2344-8

Yonemura S, Hirao M, Doi Y, Takahashi N, Kondo T, Tsukita $\mathrm{S}$. Ezrin/radixin/moesin (ERM) proteins bind to a positively charged amino acid cluster in the juxta-membrane cytoplasmic domain of CD44, CD43, and ICAM-2. J Cell Biol 1998;140:885-95 